\title{
LOS DERECHOS DEL NIÑO Y LA PROTECCIÓN A LA FAMILIA. EL CASO FORNERÓN E HIJA VS. ARGENTINA DE LA CORTE INTERAMERICANA DE DERECHOS HUMANOS
}

THE RIGHTS OF THE CHILD AND THE PROTECTION OF THE FAMILY. The Fornerón AND DAUGHTER VS. ARGENTINA CASE BEFOre the INTER-AMERICAN COURT OF HUMAN RigHTS LES DROIT DE L'ENFANT ET LA PROTECTION DE LA FAMILLE. LE CAS FORNERÓN ET FILLE VS. ARGENTINA DE LA Cour InTERAmericaine de Droit de l'Homme

LuCÍA RiziK Mulet ${ }^{* *}$

RESUMEN

El presente trabajo analiza el derecho y la protección de la familia en relación a los derechos del niño en la sentencia de la Corte Interamericana de Derechos Humanos sobre la responsabilidad de Argentina por la violación a los derechos establecidos en los articulo 17 y 19 de la Convención Americana de Derechos Humanos, en perjuicio de Leonardo Fornerón y de su hija M., a propósito del ejercicio de la guarda y custodia de la niña por parte de terceros en perjuicio de su padre, negándosele sistemáticamente la restitución, muchas veces basándose en estereotipos.

PALABRAS CLAVE: Derechos del Niño - Protección a la Familia - Corte Interamericana - Interés superior del niño - Derecho del niño a ser escuchado

ABSTRACT

This paper analyzes the right and the protection of the family in relation to the rights of the child in the decision of the Inter-American Court of Human Rights regarding the responsibility of Argentina due to the violation of the rights set forth in articles 17 and 19 of the American Convention on Human Rights, to the detriment of Leonardo Fornerón and his daughter M., concerning the exercise of the child's care and custody by third parties to the detriment of her father, who was systematically denied the child's restitution, often based on stereotypes.

KEYWORDS: Rights of the Child-Protection of the Family - Inter-American Court of Human Rights - Best interest of the child - Right of the child to be heard

* Artículo recibido el 5 de mayo de 2014 y aceptado para su publicación el 15 de septiembre de 2014.

** Abogada. Licenciada en Ciencias Jurídicas y Sociales por la Universidad de Chile. Máster en Necesidades, Derechos y Cooperación al Desarrollo en Infancia y Adolescencia, Universidad Autónoma de Madrid. Máster en Derecho Privado, Universidad Carlos III de Madrid. Estudiante de Doctorado, Universidad Diego Portales, Santiago, Chile. Correo electrónico: luciarizik@gmail.com. 
RÉSUMÉ

On envisage dans cette chronique le droit et la protection de la famille en rapport aux droits de l'enfant dans l'arrêt de la Cour Interamericaine de droit de l'homme à propos de la responsabilitè de l'Argentine par l'infraction aux droits prévus dans les articles 17 et 19 de la Convention Americaine de Droits de l'Homme, au tort de Leonardo Fornerón et sa fille M., à propos de l'exercise de la garde et custodie de la fille par tiers au tort de son père, en nient de façon systématique la restitution, en se justifient dans des stéréotypes.

MOTS CLÉS: Droits de l'enfants - Protection de la famille - Cour Interamericaine - Intérêt supérieur de l'enfant - Droit de l'enfat à être entendu

\section{INTRODUCCIÓN}

El presente comentario aborda la sentencia de la Corte Interamericana de Derechos Humanos (en adelante, Corte IDH) en el caso "Fornerón e hija vs. Argentina", del 27 de abril del año 2012, la que declara al Estado argentino responsable de la violación del derecho a la protección de la familia y de los derechos del niño, consagrados en los artículos 17.1 y 19 de la Convención Americana de Derechos Humanos (en adelante, CADH) ${ }^{1}$. Puedo adelantar que la sentencia confirma los estándares establecidos en la Opinión Consultiva OC-17/2002, sobre Condición Jurídica y Derechos Humanos del Niño (en adelante, OC-17/2002), y agrega nuevas perspectivas de interpretación del derecho a la protección de la familia y los derechos del niño ${ }^{2}$. Para el comentario, realizaré una breve reseña de los hechos, las cuestiones procesales y la decisión del caso. Luego analizaré los problemas jurídicos relevantes que presenta la sentencia, en particular, referidos al derecho a la protección de la familia y los derechos del niño. Finalmente, expondré las conclusiones a las que pude arribar.

Para el comentario tendré principalmente en cuenta las anteriores sentencias de la Corte IDH en la materia, así como las Opiniones Consultivas emitidas por

\footnotetext{
${ }^{1}$ Artículo 17. "Protección a la Familia

1. La familia es el elemento natural y fundamental de la sociedad y debe ser protegida por la sociedad y el Estado.

2. Se reconoce el derecho del hombre y la mujer a contraer matrimonio y a fundar una familia si tienen la edad $y$ las condiciones requeridas para ello por las leyes internas, en la medida en que éstas no afecten al principio de no discriminación establecido en esta Convención.

3. El matrimonio no puede celebrarse sin el libre y pleno consentimiento de los contrayentes.

4. Los Estados Partes deben tomar medidas apropiadas para asegurar la igualdad de derechos y la adecuada equivalencia de responsabilidades de los cónyuges en cuanto al matrimonio, durante el matrimonio y en caso de disolución del mismo. En caso de disolución, se adoptarán disposiciones que aseguren la protección necesaria de los hijos, sobre la base única del interés y conveniencia de ellos.

5. La ley debe reconocer iguales derechos tanto a los hijos nacidos fuera de matrimonio como a los nacidos dentro del mismo".

Artículo 19. "Derechos del Niño

Todo niño tiene derecho a las medidas de protección que su condición de menor requieren por parte de su familia, de la sociedad y del Estado".

${ }^{2}$ Corte IDH. Condición Jurídica y Derechos Humanos del Niño. Opinión consultiva OC-17/2002, 28 de agosto de 2002. Serie A No 17.
} 
ella, y tambien las Observaciones Generales del Comité de Derechos del Niño, en virtud de la legítima interpretación que realiza de la Convención sobre los Derechos del Niño (en adelante, CDN).

\section{Contexto de la SENTEnCia}

\subsection{Los hechos}

El 16 de junio de 2000, nació M., hija de Diana Elizabeth Enríquez y del señor Fornerón. El señor Fornerón desconoció la existencia del embarazo de la señora Enríquez hasta aproximadamente el quinto mes del mismo. La señora Enríquez negó al señor Fornerón que él fuera el padre.

Al día siguiente del nacimiento de la niña, la señora Enríquez entregó su hija a un matrimonio, a través de la intervención del Defensor de Pobres y Menores Suplente de la ciudad de Victoria, quien mediante un acta formal dejó constancia de lo sucedido. En el acta, la madre manifiesta que entrega a la niña en guarda provisoria con el propósito de concretar una futura adopción. Además, expresó su deseo de no ser citada a los trámites judiciales relativos a la guarda o la adopción plena.

El señor Fornerón, al conocer el nacimiento de la niña, se dirigió a diversas instituciones públicas con el objeto manifestar su interés por cuidar de la niña, e incluso, un mes y 15 días después de su nacimiento, procedió a su inscripción en el Registro Civil.

Entre el nacimiento de la niña, el 16 de junio del año 2000, y la presentación de la petición ante la Comisión Interamericana de Derechos Humanos (en adelante, CIDH), el 17 de octubre de 2004, se llevaron a cabo una serie de procedimiento judiciales, en los que se produjeron violaciones específicas de los derechos contenidos en la $\mathrm{CADH}$, en particular, el derecho a la protección judicial establecido en el artículo 25, en relación con el artículo 8.1, en cuanto a que las víctimas no tuvieron acceso a procedimientos judiciales sustentados dentro de un plazo razonable, con el cumplimiento de las debidas garantías judiciales, lo que impidió dar una adecuada protección a los derechos de la niña, establecidos en el artículo 19 de la CADH y al ejercicio del artículo 17 de la CADH relativo a la protección de la familia ${ }^{3}$.

Durante esos cuatro años, el señor Fornerón pudo reunirse una vez con su hija, durante 45 minutos, conforme fue acreditado en el proceso desarrollado ante la Corte IDH.

\footnotetext{
${ }^{3}$ La petición ante la CIDH, fue presentada por Leonardo Aníbal Javier Fornerón y por Margarita Rosa Nicoliche, esta última, representante legal del Centro de Estudios Sociales y Políticos para el Desarrollo Humano. Ante la Corte IDH, la CIDH denunció cuatro procedimientos realizados ante los tribunales judiciales argentinos, a saber: causa penal por la posible comisión del delito de supresión del estado civil (2000), la causa caratulada "M/guarda judicial" (2000) donde el matrimonio adoptante solicita la guarda judicial de la niña, la causa caratulada Fornerón/Derecho a visitas (2001), y la causa Fornerón/Adopción plena (2004). CIDH. Informe de Fondo No 83/10 Caso No 12.584, Milagros Fornerón y Leonardo Aníbal Javier Fornerón, Argentina. Washington D.C., 29 de noviembre de 2010.
} 
Las vulneraciones a los derechos de las víctimas se produjeron durante los procedimientos de guarda, régimen de visitas y adopción de la niña. El proceso de guarda de la niña, en el que se definió de manera definitiva que la niña no estaría al cuidado de su padre, tuvo una duración de tres años y cuatro meses, y en las distintas etapas, el transcurso del tiempo fue un elemento definitorio en las decisiones de Tribunales y peritos para negar el cuidado de la niña al padre, sin que se tomaran medidas que evitaran o remediaran la demora. Conforme transcurrió el tiempo, la niña creó mayores vínculos con los guardadores, un factor que se utilizó para mantener la adopción y rechazar las solicitudes del padre biológico. También fue determinante en la decisión, la posición estereotipada de la familia, teniendo una idea preconcebida de lo que es ser progenitor único.

Respecto a la solicitud de un régimen de visitas, hasta la fecha de la presentación del Informe de Fondo, no se ordenó ni implementó un régimen de visitas, pese a las múltiples solicitudes del Sr. Fornerón, y cuya posibilidad de implementación, había sido reconocida en dos sentencias por los tribunales argentinos.

Finalmente, en el procedimiento de adopción, la determinación del Estado argentino de otorgar una guarda judicial y posteriormente una adopción, a pocos días del nacimiento de la niña, sin el conocimiento inicial y luego, en oposición a la voluntad del padre biológico, constituyó una restricción ilegítima del derecho de familia del Sr. Fornerón y de su hija. Lo anterior, por cuanto dicha decisión, sin haber asegurado debidamente el acceso del padre a la niña, no sólo interfirió en el ejercicio del derecho de familia, sino que trajo aparejado adicionalmente el riesgo que se generaran lazos afectivos con el tiempo que luego sería difícil revertir, sin generar un daño a la niña. Esta decisión puso en peligro el desarrollo de los lazos de familia del Sr. Fornerón con su hija, poniendo en marcha un proceso que con el tiempo hace cada vez más difícil la restauración de los vínculos. Dicho proceso colocó al Sr. Fornerón en una situación de desventaja en relación con los solicitantes de adopción, violando su derecho a protección de la familia.

\subsection{El trámite ante el Sistema Interamericano}

El caso se inicia con una denuncia, presentada por los representantes del Sr. Fornerón y su hija, ante la Secretaría Ejecutiva de la Comisión el 14 de octubre de 2004, contra el Estado Argentino.

El Informe de Admisibilidad fue aprobado el 26 de octubre del 2006, y en la misma oportunidad, la CIDH se puso a disposición de las partes a fin de llegar a una solución amistosa del asunto, conforme al artículo 48.1 letra f) de la CADH.

Fracasado el proceso de solución amistosa, el 13 de julio de 2010, la CIDH presentó el Informe de Fondo No 83/10 sobre el caso, notificándolo al Estado argentino el 29 de julio de 2010 y otorgándole un plazo de dos meses para informar sobre el cumplimiento de las recomendaciones. El Informe de fondo recomendó: 
"1. Adoptar en el corto plazo todas las medidas necesarias para reparar de una manera integral las violaciones a los derechos humanos del señor Leonardo Aníbal Javier Fornerón y de Milagros que se determinaron en el presente informe, con la asistencia apropiada y tomando en consideración el interés superior de la niña.

2. Adoptar, entre otras medidas, de manera urgente, las acciones necesarias para crear las condiciones necesarias para establecer la relación entre Leonardo Fornerón y Milagros. 3. Investigar y aplicar las medidas o sanciones pertinentes a todos los funcionarios públicos que resulten responsables de las violaciones establecidas en el presente informe. 4. Promover la capacitación de jueces y otros funcionarios relevantes sobre los derechos integrales de la niñez relativos al mejor interés del niño o niña.

5. Adoptar las medidas legislativas o de otro carácter necesarias para prevenir y sancionar la venta de niñas y niños, de manera de cumplir sus obligaciones establecidas en la Convención Americana sobre Derechos Humanos”“.

El 23 de noviembre de 2010, el Estado argentino informó sobre las medidas adoptadas dando cumplimiento a dos de las cinco recomendaciones formuladas. Ante el fracaso en la adopción de las medidas propuestas, el 29 de noviembre del año 2010, la CIDH sometió el caso a la jurisdicción de la Corte IDH.

El 31 de enero y el 3 de febrero de 2011 se notificó el sometimiento del caso a los peticionarios y al Estado. El 1 de abril de 2011 las representantes de las víctimas remitieron su escrito de solicitudes, argumentos y pruebas. El 11 de julio de 2011 el Estado contestó a los escritos de sometimiento del caso y de solicitudes y argumentos. Con posterioridad la Corte IDH recibió declaraciones de testigos y el dictamen de un perito. El 11 de octubre de 2011 se celebró audiencia pública recibiendo la declaración del señor Fornerón, así como otras declaraciones propuestas por el Estado y la CIDH, y se realizaron los alegatos finales orales de las representantes de las víctimas y del Estado, y las observaciones finales orales de la CIDH sobre el fondo, las reparaciones y las costas. La Corte IDH, como medida para mejor resolver solicitó a Argentina algunos documentos referidos al caso.

En la sentencia no consta que Milagros, la víctima menor de edad, ejerciera directamente su derecho a ser escuchada en el proceso ante la Corte IDH. Tampoco se cuestionó si el señor Fornerón representaba adecuadamente los intereses de la niña, o si podía haber colisión entre los intereses del padre y los de su hija.

\subsection{La solución}

La Corte IDH declaró por unanimidad de sus miembros que el Estado fue responsable por la violación de los derechos a las garantías judiciales y a la protección judicial consagrados en los artículos 8.1 y 25.1 de la Convención Americana, en relación con los artículos 1.1 y 17.1 de la misma, en perjuicio del señor Fornerón y de su hija M., así como en relación con el artículo 19 del mismo instrumento

${ }^{4}$ CIDH. Informe de Fondo No 83/10 Caso No 12.584, Milagros Fornerón y Leonardo Aníbal Javier Fornerón, Argentina. Washington D.C., 29 de noviembre de 2010, párr. 136. 
en perjuicio de esta última. También fue responsable por la violación del derecho a la protección a la familia reconocido en el artículo 17.1 de la Convención Americana, en relación con los artículos 1.1, 8.1 y 25.1 de la misma, en perjuicio del señor Fornerón y de su hija M., así como en relación con el artículo 19 del mismo instrumento en perjuicio de esta última. Finalmente la Corte IDH declaró que el Estado incumplió su obligación de adoptar las disposiciones de derecho interno, establecida en el artículo $2^{\circ}$ de la Convención Americana, en relación con los artículos 19, 8.1, 25.1 y 1.1 de la misma, en perjuicio de la niña Milagros y del señor Fornerón.

La Corte IDH dispuso, que si bien lo que correspondería era dejar sin efecto los procesos judiciales que llevaron a la entrega de la guarda y custodia de la niña (y por lo tanto, restituir la niña a su padre), no fue posible obviar la circunstancia de que ha desarrollado vínculos con sus padres adoptivos y con el entorno social en que se desenvuelve, por lo que el Estado deberá establecer de manera inmediata un procedimiento orientado a la efectiva vinculación entre el señor Fornerón y su hija M., y Argentina deberá informar a la Corte sobre las características, el desarrollo y los avances del proceso de vinculación, cada cuatro meses durante dos años 5 .

\section{Problemas jurídicos}

\subsection{El concepto de familia}

La familia es objeto de protección en diversos instrumentos internacionales ${ }^{6}$. En el Sistema Interamericano de Derechos Humanos, es parte de la Declaración de Derechos y Deberes del Hombre (en adelante, DDDH), y reconocida en la $\mathrm{CADH}$ y en el Protocolo Adicional a la Convención Americana de Derechos Humanos en materia de derechos económicos, sociales y culturales (en adelante, "Protocolo de San Salvador"). Tanto la DDDH como el Protocolo de San Salvador, establecen el derecho a constituir una familia. La CADH y el Protocolo de San Salvador consagran además, el deber del Estado de protegerla. Fuera del

\footnotetext{
${ }^{5}$ En las medidas de reparación, la Corte IDH también dispuso medidas destinadas a la búsqueda de la responsabilidad de funcionarios judiciales, tipificar la venta de niños y niñas, implementar un programa dirigido a operadores judiciales, que contemple, entre otros, los estándares internacionales en derechos humanos, particularmente, en materia de los derechos de los niños y niñas y su interés superior y el principio de no discriminación, publicar el resumen oficial de la sentencia, pagar indemnización por daño material e inmaterial, por el reintegro de costas y gastos, así como reintegrar al Fondo de Asistencia Legal de Víctimas, y rendir al Tribunal un informe sobre las medidas adoptadas para cumplir con la misma. Sobre las medidas de reparación, Cfr. Caso "Fornerón e hija vs. Argentina”, 27 de abril de 2012, Serie C No 242, párr. 149 y ss.

${ }^{6}$ A modo de ejemplo, podemos nombrar las siguientes normas internacionales vinculadas con el Derecho a la Familia y su protección: artículo 16 de la Declaración Universal de Derechos Humanos (1948); artículo 23 del Pacto Internacional de Derechos Civiles y Políticos (1966); o los artículos 4, 44, 45 y 50 de la Convención Internacional sobre la Protección de los Derechos de todos los Trabajadores Migratorios y sus Familiares (1990).
} 
sistema interamericano, la familia es un elemento relevante en la Convención sobre derechos del niño (en adelante, $\mathrm{CDN}$ ), refiriéndose a ella tanto en el preámbulo como en el articulado.

El contenido y el alcance del derecho de protección a la familia han sido desarrollados en la opinión consultiva OC-17/2002 emitida por la Corte IDH en el ejercicio de su competencia para la interpretación de la $\mathrm{CADH}^{7}$. La Corte IDH También ha tenido oportunidad de referirse a este derecho y declarar la violación del mismo en variados $\operatorname{casos}^{8}$. Sin embargo, no existe una definición general de "familia" en la normativa interamericana ni en otros instrumentos internacionales? La construcción del concepto ha sido jurisprudencial e interpretativa.

El artículo 17.1 de la CADH establece el deber de la sociedad y del Estado de proteger a la familia, sin distinguir cuáles. Considerando que el artículo 29 de la $\mathrm{CADH}$ impide que los derechos reconocidos en la $\mathrm{CADH}$ sean interpretados de forma que supriman o limiten su goce y ejercicio, la protección del artículo 17.1 abarcaría a todas las familias, sin distinciones, exclusiones ni restricciones ${ }^{10}$. Para la Corte IDH, la imposición de un concepto único de familia no es sólo una vulneración al artículo 17 de la $\mathrm{CADH}$ sino también una injerencia arbitraria y

\footnotetext{
${ }^{7}$ La facultad de someter a consulta de la Corte la interpretación de la CADH o de otros instrumentos del sistema, se encuentra establecida en el artículo 64.1 de la CADH.

${ }^{8}$ Entre otras: caso "Chitay Nech y otros vs. Guatemala", 25 de mayo de 2010, Serie C No 212. Luego se ha pronunciado en las siguientes sentencias: caso "Gelman vs. Uruguay", 24 de febrero de 2011, Serie C No 221; caso "Contreras vs. El Salvador", 31 de agosto de 2001, Serie C No 232, caso "Atala e hijas vs. Chile", 24 de febrero de 2012, Serie C No 239, y caso "Artavia Murillo y otros vs. Costa Rica", 28 de noviembre de 2012, Serie C No 257.

9 Probablemente, la única definición en el Derecho Internacional de Protección de los Derechos Humanos sobre el asunto sea la contenida en el artículo $4^{\circ}$ de la Convención Internacional sobre la protección de los derechos de todos los trabajadores migratorios y de sus familiares, que señala: " $A$ los efectos de la presente Convención, el término 'familiares' se refiere a las personas casadas con trabajadores migratorios o que mantengan con ellos una relación que, de conformidad con el derecho aplicable, produzca efectos equivalentes al matrimonio, asi como a los hijos a su cargo y a otras personas a su cargo reconocidas como familiares por la legislación aplicable o por acuerdos bilaterales o multilaterales aplicables entre los Estados de que se trate". Convención Internacional sobre la protección de los Derechos de todos los Trabajadores Migratorios y de sus Familiares, Diario Oficial, 8 de abril de 2005. Al respecto, Sanz Caballero, considera "existe bastante tolerancia en NU sobre el concepto de familia. En lugar de una familia modelo se suele tomar como referencia modelos de familia. No existe un enfoque unidireccional ni una definición estricta de la institución. La justificación para ello es que, de otro modo, se correría el riesgo de prejuzgar alguna situación, excluyéndola del ámbito de las relaciones familiares y dejándola sin protección. De hecho, cualquier intento emprendido por la ONU con el fin de lograr un consenso sobre la definición y la terminología aplicables a la familia o los hogares familiares se ha saldado siempre en un absoluto fracaso. Sin embargo, esta amplitud en la forma de entender el término familia ha sido muy criticada desde distintas instancias, especialmente desde la Santa Sede”. Sanz Caballero, Susana (2006). La familia en la perspectiva internacional y europea. Madrid: Editorial Tirant Lo Blanch, $1^{\text {a }}$ edición, p. 27.

${ }^{10}$ Cfr. Badilla, Ana (2006). "El derecho a la constitución y la protección de la familia en la normativa y la jurisprudencia del Sistema Interamericano de Derechos Humanos". En: Interpretación de los principios de igualdad y no discriminación para los derechos de las mujeres en los instrumentos del Sistema Interamericano, San José de Costa Rica: Editorial Instituto Interamericano de Derechos Humanos, 1a edición, p. 109.
} 
abusiva en la vida familiar de las personas ${ }^{11}$, de conformidad al artículo $11.2 \mathrm{de}$ la $\mathrm{CADH}^{12}$.

Asimismo, se ha declarado que el concepto de familia es amplio y variable. Es amplio, porque en él caben todas las estructuras familiares vinculadas por un parentesco cercano ${ }^{13}$, permitiendo que bajo la CADH pueda protegerse modelos de familia no tradicional, abarcando lazos familiares de hecho donde las partes tengan vida en común fuera del matrimonio ${ }^{14}$ e incluso modelos familiares poligámicos ${ }^{15}$. Es variable, porque la forma y el concepto de familia no es igual en un Estado $\mathrm{u}$ otro, ni siquiera en una región u otra en un mismo Estado ${ }^{16}$.

En la CDN el concepto de familia es aún más amplio. El preámbulo de la Convención sobre derechos del niño, se refiere a ella como "el grupo fundamental de la sociedad y medio natural para el crecimiento y el bienestar de todos sus miembros, y en particular de los niños". Conforme a lo dispuesto en el artículo $5^{\circ}$ de la CDN, la estructura familiar puede incluir a la familia ampliada y a la comunidad, y no sólo a los padres. Al respecto, el Comité de Derechos del niño estima que la familia incluye a una variedad de estructuras que pueden ocuparse del bienestar

${ }^{11}$ En el caso "Atala e hijas vs. Chile", la Corte IDH señaló que" a diferencia de lo dispuesto en el Convenio Europeo, en el cual sólo se protege el derecho a la vida familiar bajo el artículo 8 de dicho Convenio, la Convención Americana cuenta con dos artículos que protegen la vida familiar de manera complementaria. En efecto, esta Corte considera que la imposición de un concepto unico de familia debe analizarse no sólo como una posible injerencia arbitraria contra la vida privada, según el artículo 11.2 de la Convención Americana, sino también, por el impacto que ello pueda tener en un núcleo familiar, a la luz del artículo 17.1 de dicha Convención". Caso "Atala e hijas vs. Chile", 24 de febrero de 2012, Serie C No 239, párr. 142; Opinión consultiva OC-17/2002, párr. 69.

${ }^{12}$ Artículo 11. "Protección de la Honra y de la Dignidad.

1. Toda persona tiene derecho al respeto de su honra y al reconocimiento de su dignidad.

2. Nadie puede ser objeto de injerencias arbitrarias o abusivas en su vida privada, en la de su familia, en su domicilio o en su correspondencia, ni de ataques ilegales a su honra o reputación.

3. Toda persona tiene derecho a la protección de la ley contra esas injerencias o esos ataques".

${ }^{13}$ Caso "Molina Thiessen vs. Guatemala", 3 de julio de 2004, Serie C No 108; párr. 48; Opinión consultiva OC-17/2002, párr. 70; Caso "Trujillo Oroza vs. Bolivia”, 27 de febrero de 2002, Serie C No 92, párr. 57; Caso "Bámaca Velasquez vs. Guatemala”, 22 de febrero de 2002, Serie C No 91, párr. 34; Caso "Villagrán Morales y otros ('niños de la calle') vs. Guatemala”, 26 de mayo de 2001, Serie C No 77, párr. 68.

${ }^{14}$ Caso "Atala e hijas vs. Chile", 24 de febrero de 2012, Serie C No 239, párr. 142; Opinión consultiva OC17/2002, párr. 69. Asimismo, la Corte IDH, con el objeto de establecer las indemnizaciones y reparaciones a los familiares de la víctima por violaciones a los derechos establecidos en la CADH, ha reconocido como familiares a concubinas, compañeras, compañeros e hijastros. Cfr. "Caso Velásquez Rodríguez vs. Honduras", 21 de julio de 1989. Serie C No 07, párr. 13; caso "El Amparo vs. Venezuela", 14 de septiembre de 1996. Serie C No 28, párr. 41; caso "Masacre de La Rochela vs. Colombia”, 11 de mayo de 2007. Serie C No 163, párr. 268; caso "Tibi vs. Ecuador", 7 de septiembre de 2004. Serie C No 114, párrs. 160-162.

15 En el caso "Aloeboetoe y otros vs. Surinam" la estructura familiar poligámica y matriarcal de la comunidad indígena maroons, fue admitida por la Corte IDH, a solicitud de la Comisión IDH, aunque únicamente para establecer las reparaciones de los familiares de las víctimas, indemnizando en su calidad de sucesores de las víctimas de violaciones de los derechos humanos a las cónyuges (cuatro víctimas tenían dos esposas cada uno) y sus hijos. caso "Aloeboetoe y otros vs. Surinam", 10 de septiembre de 1993, Serie C No 15.

${ }^{16}$ Caso "Atala e hijas vs. Chile”, 24 de febrero de 2012, Serie C No 239, párr. 172. 
y la protección de NNA -niños, niñas y adolescentes-. Estas estructuras pueden ser la familia nuclear, la familia ampliada y otras modalidades tradicionales y modernas de base comunitaria, siempre que sean acordes con los derechos y el interés superior de $\mathrm{NNA}^{17}$.

En la sentencia del caso Fornerón e hija vs. Argentina, la Corte IDH estableció que los fundamentos de los Tribunales argentinos para otorgar la guarda judicial, respondieron a "una idea preconcebida de lo que es ser progenitor único, ya que el señor Fornerón se le cuestionó y condicionó su capacidad y posibilidad de ejercer su función de padre a la existencia de una esposa"18. La Corte IDH afirmó además, que "no hay nada que indique que las familias monoparentales no puedan brindar cuidado, sustento y cariño a los niños. La realidad demuestra cotidianamente que no en toda familia existe una figura materna o una paterna, sin que ello obste a que ésta pueda brindar el bienestar necesario para el desarrollo de los niños y niñas" ${ }^{19}$, y agregó que la niña tiene el derecho a crecer con su familia de origen ${ }^{20}$. Estas afirmaciones son coherentes con lo expuesto por la Corte IDH en sus opiniones consultivas y en la jurisprudencia. Continúa en la línea de reconocer y resguardar los variados tipos de estructuras familiares que pueden presentarse (en este caso la familia monoparental), descartando la posibilidad de que el ejercicio del derecho a constituir una familia pueda limitarse o restringirse únicamente por la forma en que se organiza o por la condición de los miembros que la componen.

\subsection{Las medidas de protección a la familia y los derechos del niño}

El caso Fornerón e hija vs. Argentina, agrega un nuevo criterio para la concreción del deber del Estado de proteger a la familia. Considera a la familia biológica el objeto primordial de las medidas de protección del Estado, pues es a ésta a la que NNA tienen principalmente derecho. La familia biológica incluye a los familiares más cercanos. Por lo tanto, a falta de uno de los padres, las autoridades judiciales se encuentran en la obligación de buscar al padre, madre u otros familiares biológicos ${ }^{21}$. Pero, la familia biológica como objeto primordial de las medidas de protección del Estado ¡es una nueva pauta interpretativa de la Corte IDH?

Revisada la jurisprudencia de la Corte IDH, puede apreciarse que las medidas de protección a la familia en relación con los derechos de NNA se sustentan sobre dos pilares. Primero, el artículo 19 de la CADH conforme al cual, NNA tienen derecho a recibir la protección que su condición requiera por parte de la

\footnotetext{
${ }_{17}$ Comité de Derechos del Niño. Realización de los Derechos del Niño en la primera Infancia. Observación General No 7, Ginebra, 20 de septiembre de 2005, CRC/C/GC/7/Rev. 1, párr. 15.

${ }^{18}$ Caso “Fornerón e hija vs. Argentina”, 27 de abril de 2012, Serie C № 242, párr. 96.

19 Ibíd., párr. 98.

${ }^{20}$ Ibíd., párr. 119.

21 Ídem.
} 
familia, la sociedad y el Estado. Segundo, en lo que ya es jurisprudencia constante de la Corte IDH, es la familia, en principio, quien debe proporcionar la mejor protección a los NNA contra el abuso, el descuido y la explotación, y por lo tanto, el Estado está obligado a favorecer de la manera más amplia el desarrollo y la fortaleza del núcleo familiar ${ }^{22}$. El derecho de los NNA a recibir la protección de su familia envuelve, entre otros: el derecho a vivir con ella, el derecho a crecer en su familia de origen, el derecho a no ser separado de sus padres y el derecho a su identidad.

Los NNA tienen derecho a vivir con su familia, pues es ésta la llamada a satisfacer las necesidades materiales, afectivas y psicológicas de $\mathrm{NNA}^{23}$. La separación de NNA de su familia constituye bajo ciertas condiciones una violación al artículo 17 de la CADH, por lo tanto, cuando estas sean legales "solo pueden proceder si están debidamente justificadas en el interés superior del niño, son excepcionales y, en lo posible, temporales"24. La falta de recursos materiales no puede ser el único fundamento para una decisión que suponga la separación de los NNA de su familia, pues le priva de otros derechos consagrados en la $\mathrm{CDN}^{25}$. Tampoco pueden serlo "las especulaciones, presunciones, estereotipos o consideraciones generalizadas sobre caracteristicas personales de los padres o preferencias culturales respecto a ciertos conceptos tradicionales de la familia" ${ }^{26}$, como reiteró la Corte IDH en la sentencia en comento, siguiendo lo ya establecido en el caso Atala e hijas vs. Chile.

El derecho a crecer en su familia de origen, fue reconocido por la Corte IDH en el caso Gelman vs. Uruguay. Allí señaló que las injerencias arbitrarias a tan corta edad vulneran los derechos de NNA y la protección a la familia ${ }^{27}$. La sentencia que aquí se analiza también incluye este derecho, y considera que la hija del señor Fornerón, al no tener contacto con su familia de origen, fue impedida de crear las relaciones familiares que jurídicamente le corresponden ${ }^{28}$. La falta de vínculos con su familia de origen tiene como consecuencia la vulneración del derecho a la identidad. El derecho a la identidad reconocido en la CDN incluye el de preservar la nacionalidad, el nombre y las relaciones familiares sin injerencias arbitrarias. Sería el derecho a la identidad en su tercer aspecto, es decir, las relaciones familiares el que fue afectado por el Estado argentino, pues la niña estuvo impedida de crecer junto a su familia biológica al establecerse la guarda

\footnotetext{
22 Opinión Consultiva OC-17/2002, párr. 66.

${ }^{23}$ Opinión Consultiva OC-17/2002, párr. 71.

${ }^{24}$ Caso "Gelman vs. Uruguay", párr. 125; Caso “Fornerón e hija vs. Argentina”, 27 de abril de 2012, Serie C No 242, párr. 47; Opinión Consultiva OC-17/02, párrs. 72, 75 y 77.

25 Opinión Consultiva OC-17/2002, párr. 77.

${ }^{26}$ Cfr. caso "Fornerón e hija vs. Argentina", 27 de abril de 2012. Serie C No 242, párr. 50; caso "Atala e hijas vs. Chile”, 24 de febrero de 2012, Serie C No 239, párr. 109.

27 Cfr. caso "Fornerón e hija vs. Argentina", 27 de abril de 2012, Serie C No 242, párr. 119.

${ }^{28}$ Ibíd., párr. 123.
} 
judicial a otra familia, y no se le permitió tener contacto o vínculos con su familia de origen, impidiéndole crear relaciones familiares con ésta, al no materializarse un régimen de visitas ${ }^{29}$.

En estrecha relación al derecho a crecer con su familia de origen, está el derecho a no ser separados de sus padres, establecido en el artículo 9.1 y 9.3 de la $\mathrm{CDN}^{30}$. El cuidado y la protección de los padres con sus hijos es una idea que figuraba ya en la Declaración de los Derechos del Niño de 1959, antecedente directo de la CDN. El principio No 6 de la Declaración estipulaba que "El niño, para el pleno y armonioso desarrollo de su personalidad, necesita amor y comprensión. Siempre que sea posible, deberá crecer al amparo y bajo la responsabilidad de sus padres".

Como ya señalamos a propósito de el derecho a vivir con la familia, para decretar la separación de un NNA de su familia, y en este caso, de su padre, la medida debe justificarse en el interés superior de NNA, tener el carácter de excepcional y en lo posible, temporal. Para que la medida se justifique en el propio interés de NNA, en casos de cuidado y custodia de menores de edad, se deben evaluar "los comportamientos parentales especificos y su impacto negativo en el bienestar y desarrollo del niño según el caso, los daños o riesgos reales, probados y no especulativos o imaginarios en el bienestar del niño" 1 , lo que no se hizo en el caso del señor Fornerón y su hija. Tampoco se cumplió con la excepcionalidad de la separación ya que no se consideró la voluntad del padre ni se apreció la existencia de circunstancias excepcionales que autorizacen a los tribunales a separar al señor Fornerón de su hija ${ }^{32}$.

Conforme a lo expuesto anteriormente, puede apreciarse que la familia biológica, como objeto primordial de protección del Estado, es un mandato general

\footnotetext{
${ }^{29} \mathrm{La} \mathrm{CIDH}$ alegó que "el Estado no ha tomado las medidas necesarias para implementar un régimen de visitas oportuno, por lo que la niña ha sido privada de su derecho a acceder a diversos aspectos de la identidad, de contar con información importante para su desarrollo y de establecer vinculos con su familia biológica. Las relaciones familiares y los aspectos biológicos de la historia de una persona, particularmente de un niño o una niña, constituyen parte fundamental de su identidad, por lo que, toda acción u omisión del Estado que tenga efectos sobre tales componentes, puede constituir una violación del derecho a la identidad. En este sentido, la conducta de las autoridades internas que otorgaron la guarda y la adopción comprometió la responsabilidad internacional del Estado para la violación de los derechos a la familia y a la identidad". Caso "Fornerón e hija vs. Argentina", 27 de abril de 2012, Serie C No 242, párr. 113.

${ }^{30}$ Artículo 9o $\mathrm{CDN}$ :

"1. Los Estados Partes velarán porque el niño no sea separado de sus padres contra la voluntad de éstos, excepto cuando, a reserva de revisión judicial, las autoridades competentes determinen, de conformidad con la ley y los procedimientos aplicables, que tal separación es necesaria en el interés superior del niño. Tal determinación puede ser necesaria en casos particulares, por ejemplo, en los casos en que el niño sea objeto de maltrato o descuido por parte de sus padres o cuando éstos viven separados y debe adoptarse una decisión acerca del lugar de residencia del niño. 3. Los Estados Partes respetarán el derecho del niño que esté separado de uno o de ambos padres a mantener relaciones personales y contacto directo con ambos padres de modo regular, salvo si ello es contrario al interés superior del niño".

${ }^{31}$ Caso "Fornerón e hija vs. Argentina”, 27 de abril de 2012, Serie C No 242, párr. 50.

${ }^{32}$ Ibíd., párr. 121.
} 
que la Corte IDH ya venía construyendo en su jurisprudencia. Los antecedentes directos son el derecho de NNA a crecer con su familia de origen, el derecho a vivir con su familia y a no ser separado de sus padres y el derecho a preservar la identidad de las relaciones familiares.

\section{CONCLUSIONES}

La protección a la familia y los derechos del niño tienen una especial relevancia en la $\mathrm{CADH}$, que se manifiesta por ejemplo, en la imposibilidad de suspender su vigencia. En el presente caso, la Corte IDH interpreta y aplica estos preceptos de conformidad a sus resoluciones anteriores, y resuelve por unanimidad. La sentencia otorga mayor comprensión sobre la significación y trascendencia de los derechos del niño en el sistema. En particular, confirma la opinión sobre la amplitud y variabilidad del concepto de familia, siendo inadmisibles las preferencias sobre concepciones tradicionales de la misma. El concepto de familia incluye distintas estructuras familiares, en este caso, el Estado debe proteger a las familias monoparentales, conformadas por padre e hija. Asimismo, insiste en que la separación de un NNA de sus padres requiere del cumplimiento de una serie de requisitos para que tal medida se justifique en su interés superior.

Si bien todas las familias deben ser objeto de protección, en esta sentencia la Corte IDH afirma, sin eufemismos, su preferencia por la familia biológica. Es a ésta a la que el Estado debe proteger de forma primordial y a la que NNA tienen principalmente derecho. Nunca antes la Corte IDH se había referido en estos términos a un tipo de familia. La sentencia confirma el importante rol que ha tenido la familia biológica en anteriores sentencias, a través de pronunciamientos sobre el derecho de NNA a vivir con su familia de origen, el derecho a no ser separados de sus padres y el derecho a la identidad. Se preferirá a la familia biológica siempre que sea posible, y, en todo caso, se debe asegurar el conocimiento de los orígenes y eventualmente relacionarse con sus familiares. Pero se trata de una pauta interpretativa, y no de un mandato general, pues está formulado con carácter relativo (primordial) y no absoluto, por lo que si el interés superior de NNA lo exige, la familia biológica puede ceder a otros tipos de familia, si esto resulta mas favorable para el desarrollo y bienestar de NNA, pero respetando su identidad biológica.

\section{BiBLIOGRAFÍA CITADA}

BADILla, Ana (2006). "El derecho a la constitución y la protección de la familia en la normativa y la jurisprudencia del Sistema Interamericano de Derechos Humanos". En: Interpretación de los principios de igualdad y no discriminación para los derechos de las mujeres en los instrumentos del Sistema Interamericano, San José de Costa Rica: Editorial Instituto Interamericano de Derechos Humanos, $1^{a}$ edición. 
SAnz Caballero, Susana (2006). La familia en la perspectiva internacional y europea. Madrid: Editorial Tirant Lo Blanch, $1^{\text {a }}$ edición.

\section{NORMAS CITADAS}

Convención Americana de Derechos Humanos, Pacto de San José de Costa Rica, Diario Oficial, 5 de enero de 1991.

Convención sobre los Derechos del Niño, Diario Oficial, 27 de septiembre de 1990.

Convención Internacional sobre la Protección de los Derechos de todos los Trabajadores Migratorios y de sus Familiares, Diario Oficial, 8 de abril de 2005.

Protocolo Adicional a la Convención Americana sobre Derechos Humanos en Materia de Derechos Económicos, Sociales y Culturales, "Protocolo de San Salvador".

\section{JURISPRUDENCIA CITADA}

Corte IDH, "Velásquez Rodríguez vs. Honduras", sentencia (reparaciones y costas), 21 de julio de 1989, Serie C No 07.

Corte IDH, "Aloeboetoe y otros vs. Surinam", sentencia (reparaciones y costas), 10 de septiembre de 1993, Serie C No 15.

Corte IDH, "El Amparo vs. Venezuela", sentencia (Reparaciones), 14 de septiembre de 1996, Serie C No 28.

Corte IDH, "Villagrán Morales y otros ('niños de la calle') vs. Guatemala”, sentencia (reparaciones y costas), 26 de mayo de 2001, Serie C No 77.

Corte IDH, "Bámaca Velásquez vs. Guatemala", sentencia (reparaciones y costas), 22 de febrero de 2002, Serie C No 91.

Corte IDH, "Trujillo Oroza vs. Bolivia", sentencia (reparaciones y costas), 27 de febrero de 2002, Serie C No 92.

Corte IDH "Molina Thiessen vs. Guatemala", sentencia (reparaciones y costas), 3 de julio de 2004, Serie C No 108.

Corte IDH, "Tibi vs. Ecuador", sentencia (excepciones preliminares, fondo, reparaciones y costas), 7 de septiembre de 2004, Serie C No 114.

Corte IDH, "Masacre de La Rochela vs. Colombia", sentencia (fondo, reparaciones y costas), 11 de mayo de 2007, Serie C No 163.

Corte IDH, "Gelman vs. Uruguay", sentencia (fondo, reparaciones y costas), 24 de febrero de 2011, Serie C No 221.

Corte IDH, "Contreras y otros vs. El Salvador", sentencia (fondo, reparaciones y costas), 31 de agosto de 2001, Serie C No 232.

Corte IDH, "Atala e hijas vs. Chile", sentencia (fondo, reparaciones y costas), 24 de febrero de 2012, Serie C No 239. 
Corte IDH, "Fornerón e hija vs. Argentina”, sentencia (fondo, reparaciones y costas), 27 de abril de 2012, Serie C No 242.

Corte IDH, “Artavia Murillo y otros ('fecundación in vitro') vs. Costa Rica”, sentencia (excepciones preliminares, fondo, reparaciones y costas), 28 de noviembre de 2012, Serie C No 257. 